\title{
MULTIPLICAÇÃO E MIOPIA
}

\section{MULTIPLICATION AND MYOPIA}

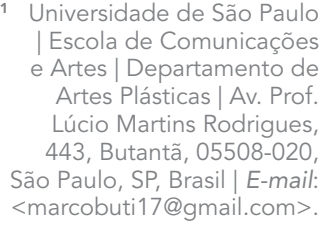

Como citar este artigo How to cite this article Buti, M. F. Multiplicação e miopia. Pós-Limiar, v. 4 e215013, 2021. https:// doi.org/10.24220/2595 $9557 v 4 \mathrm{e} 2021 \mathrm{a} 5013$

Recebido em 30/6/2020, reapresentado em 9/9/2020 aprovado em 14/10/2020

\author{
Marco Francesco Buti ${ }^{1}$ \\ ORCID iD: 0000-0002-1151-8660
}

\section{RESUMO}

"Multiplicação e Miopia" é uma série de textos de elaboração aberta, sem quantidade ou final previsto, que são escritos obedecendo à disponibilidade de tempo, surgimento de ideias ou ocasiões específicas. Tratam da arte multiplicável e se originam do meu curso de pós-graduação "Multiplicação e Miopia: um esboço não científico de uma possível inserção da estampa na História da Arte", ministrado no Programa de Pós-Graduação em Artes Visuais da Escola de Comunicações e Artes da Universidade de São Paulo (ECA-USP), de 2010 a 2013.

\section{Palavras-chave}

Arte multiplicável. Escritos. Multiplicação e miopia. Não científico, estampa.

\section{ABSTRACT}

"Multiplication and Myopia" is a series of texts in open elaboration, without a fixed quantity or a predicted end, written obeying the availability of time, the appearance of specific ideas or occasions. They deal with multipliable art, originating from my graduate course entitled "Multiplication and Myopia: a non-scientific sketch of a possible insertion of the print in the History of Art", taught in the Graduate Program in Visual Arts at the Escola de Comunicações e Artes da Universidade de São Paulo (ECA-USP), between 2010 and 2013.

\section{Keywords}

Multipliable art. Writings. Multiplication and myopia. Non-scientific, print.

Com o estabelecimento do processo de matriz e estampa, inicialmente com a xilogravura e em seguida com a gravura em metal, começavam a mudar radicalmente as possibilidades de contato com o trabalho artístico e seu potencial alcance. A obra podia ser altamente móvel, mesmo que o espectador permanecesse fixo. A noção de espaço público seria obrigada a mudar: não bastava mais a colocação em pontos tidos como de presença obrigatória. A imagem multiplicável era agora capaz de atingir muito mais pessoas do que os passantes em certo local. A imprensa se associaria em seguida a essas novas possibilidades. Imagem e letra podem acompanhar de perto os acontecimentos políticos ou provocá-los. Tudo isso começa 
a acontecer no início do século $\mathrm{XV}$, e no século seguinte está altamente organizado. Quando Lutero afixa seu famoso manifesto em Wittenberg, não se trata de um exemplar único. Muitos outros estavam circulando.

Apesar do largo tempo de existência, o conceito de obra circulante não foi bem absorvido no universo das artes visuais. $O$ espaço artístico ainda consegue ser pensado tendo limites tão definidos como a soleira da galeria e do museu, quando deveríamos pensar em zonas de transição menos bem traçadas. Trabalhos com vocação à ampla circulação, como vídeos e fotografias, seguem o modelo da pintura e da escultura única e são apresentados em espaços fechados, com acesso controlado, reivindicando um papel político. Por outro lado, instalar um trabalho em algum ponto da metrópole parece suficiente para torná-lo absolutamente público, como se o espaço público fosse apenas físico e não principalmente mental, e não fosse possível passar a vida inteira sem passar naquele ponto. Onde se situa a ágora de São Paulo?

Juntamente com a multiplicação, ia sendo formado o conceito moderno de artista, criador por excelência, procurando ser reconhecido por um nível social que não aprecia e não entende o trabalho manual. Desde o início da História da Arte, tal artista é compreendido preferencialmente como pintor, escultor ou arquiteto. Torna-se difícil, conhecendo apenas a ortodoxia, até conceber artistas que não atuam dentro de espaços oficiais ou tornados oficiais, mas se manifestam nas áreas mais vulgares dos processos de ampla circulação, tidos como comerciais, por levar em conta os interesses do público comum. É digno de nota ter-se tentado reagir ao excesso de interesses monetários através de trabalhos que se pretendem invendáveis ou são efêmeros, em lugar da possibilidade mais óbvia e secularmente estabelecida do objeto repetido a baixo preço. Desse ângulo, José Guadalupe Posada, artista atuante na imprensa industrial mexicana no século XIX e início do XX, contestaria mais a noção estabelecida de arte e de artista do que Marcel Duchamp.

Parangolé é a antiarte por excelência: inclusive pretendo estender o sentido de "apropriação" às coisas do mundo com que deparo nas ruas, terrenos baldios, campos, o mundo ambiente, enfim - coisas que não seriam transportáveis, mas para as quais eu chamaria o público à participação -, seria isso um golpe fatal ao conceito de museu, galeria de arte etc., e ao próprio conceito de "exposição" - ou nós o modificamos ou continua na mesma (Hélio Oiticica, Aspiro ao Grande Labirinto, julho 1966).

Em 1968, a Editora Abril publicava no Brasil a $1^{a}$ edição dos Gênios da Pintura, cujo exemplar inicial era dedicado a van Gogh, com um de seus mais famosos autorretratos impressos na capa. A partir de então, o interessado podia adquirir, semanalmente em bancas de jornal, um fascículo dedicado a um pintor selecionado pelos consultores artísticos da Fratelli Fabbri, editora italiana que publicara a edição original no ano anterior e detinha seu copyright. Cada exemplar continha 16 reproduções do artista, além da capa e de textos pouco aprofundados, destinados ao grande público. Mas eram as imagens artísticas mais disponíveis no Brasil naqueles anos, onde os museus e galerias eram pouco numerosos e o costume de frequentá-los restrito. Havia certa expectativa quanto ao exemplar seguinte: devia-se aguardar mais sete dias antes de leva-lo para casa, onde ficaria guardada a coleção inteira, completada em 96 semanas.

Para muitos futuros artistas, foi o primeiro contato com obras de artes visuais. 
A colagem cubista, no início do século $X X$, introduziu novos elementos no campo da pintura. Um dos mais importantes seria a incorporação de objetos do mundo ao plano pictórico. Parte deles eram impressos, extraídos de jornais e revistas. É uma preocupação retórica recorrente da Arte Moderna e Contemporânea abrir a obra ao mundo, exemplificada na supressão de molduras e pedestais - conceitual, simbólica, pouco efetiva. Mais adequada ao mundo real era a proposta de associar arte e indústria de múltiplas maneiras, cuja realização mais visível foi provavelmente o cinema.

Em novembro de 1968 foi inaugurada finalmente a atual sede do Museu de Arte de São Paulo (MASP), na Avenida Paulista, no lugar anteriormente ocupado pelo Belvedere do Trianon, local de lazer da elite paulistana. Mesmo sem cobrar ingresso ainda, o acesso às pinturas ali custodiadas era reduzido pelo próprio conceito de museu como edifício, com capacidade específica de receber público que deve se dirigir até ali, independentemente de local de residência, disponibilidade de tempo, interesse e condições econômicas.

Em 1968, o interessado podia se deparar com uma coisa do mundo nas bancas de jornal do Brasil - os Gênios da Pintura -, com reproduções impressas em escala reduzida e cores alteradas de pinturas distantes do Brasil e de algumas guardadas no interior do MASP. Essa experiência em tom menor, mas multiplicável, do contato com a arte, tinha mais possibilidades de sucesso que a exposição de um artista desconhecido do grande público propondo aproximar a arte e a vida no interior de galerias ou museus.

A multiplicação da imagem por meio da estampa multiplicada remonta ao século $\mathrm{XV}$, no Ocidente. No século seguinte, a interpretação multiplicável da pintura tinha se tornado uma atividade estabelecida e organizada, definindo seu veículo preferencial na estampa obtida a partir de matrizes de cobre gravadas a buril. Com a gravura em metal e madeira como únicas possibilidades de multiplicação da imagem, era através delas que as ideias visuais se difundiam, e menos através da pintura e escultura; obras únicas de circulação difícil, indesejada ou impossível, campo privilegiado da História da Arte.

A gráfica se definia desde o início, simultaneamente, como obra de arte e reprodução da obra de arte, ilustração de todos os gêneros, imagem clandestina - distinção enganosa. Manifestação artística autônoma e prenúncio da multiplicação industrial. No Brasil, excluindo poucas e mal estudadas tentativas ilegais, a impressão em geral foi retardada até 1808, quando a fuga da família real portuguesa extinguiu as proibições. A gravura só adquiriu alguma visibilidade no mundo artístico restrito a partir da década de 10 do século XX, com um passado resumido ao século XIX, curto e pouco pesquisado.

Seria difícil em 1968 (e ainda é), para o grande público e para artistas, historiadores, teóricos e críticos habituados a uma História da Arte convencional, perceber que os Gênios da Pintura era a versão atualizada e plenamente industrial de uma atividade de vários séculos, e que as primeiras tentativas de ligar as artes visuais à multiplicação característica da indústria datam do início do século XV. 
Essas questões, e outras, são levantadas pelo projeto de ampliar as atividades da Casa da Boia, dedicando espaço às artes visuais com foco na gráfica, sem abandonar sua atividade de fornecedor de metais não ferrosos. A distância é apenas aparente.

Fundada há 120 anos, essa loja antecede a gravura mais conhecida no Brasil, manifestação artística do Modernismo. Seria interessante investigar se gravadores em metal de fins do século XIX já recorriam à Casa da Boia para conseguir chapas de cobre. Seja como for, desde meus primeiros contatos com a gravura em metal era e continua sendo uma das principais opções de artistas, estudantes, operários e artesãos para conseguir metais indispensáveis.

Não existem materiais mais artísticos que outros. Tudo depende da intenção, do projeto, do desígnio. Do desenho, pensamento que seleciona os materiais poeticamente necessários à manifestação sensível. A loja de materiais artísticos é consequência da separação entre artista e artesão, levada a cabo no Renascimento, concomitante ao surgimento da imagem impressa multiplicável, buscando aproximar o artista das Artes Liberais e libertando-o das restrições das corporações de ofício. Essa operação para elevar o status social do artista teve êxito parcial, apesar dos numerosos casos de sucesso e mesmo de reconhecimento, além de qualquer racionalidade. Em círculos elitizados ainda existem fortes restrições aos aspectos tidos como menos "intelectuais" da atividade artística, e certo desprezo pelo trabalho em oficina. A oposta mitificação do mesmo fazer não é mais inteligente.

A proposta de unir arte e indústria tem também o aspecto de volta à situação pré-renascimental abolindo a distinção belas artes/artesanato e voltando a inserir a arte no mundo através dos novos meios técnicos disponíveis. Se pelo menos parte das vanguardas modernas históricas buscava associar a arte à mudança social, fazia sentido encontrar meios capazes de concretizar a circulação do objeto artístico em círculos mais amplos, se possível toda a sociedade, superando o confinamento dos vários gêneros de corte, supostamente abolidos ou em vias de extinção - ou transformação.

Ao longo das duas primeiras décadas do século XIX, acompanhando a Revolução Industrial, a gráfica voltada ao grande público já tinha se tornado plenamente industrializada. Abastecia - com jornais, revistas, livros, ilustrações, embalagens, manuais, partituras, propaganda - a curiosidade, o desejo de conhecimento, a ciência e as expectativas estéticas de uma sociedade que se tornava de massa. Visualmente, é o século dominado pela gráfica. Mesmo a grande influência da fotografia seria impensável sem sua associação às técnicas de multiplicação industrializadas: revelação e ampliação por processos químicos não se integrariam ao ritmo de produção já estabelecido. O cinema iniciaria apenas em 1895, mesmo ano da história em quadrinhos, produto das artes gráficas de imensa circulação.

Evidentemente, a indústria cultural produz uma larga maioria de textos e imagens de baixa qualidade e pode ser vista como oposta à cultura e à arte. Mas essa indústria contém agora a reprodução multiplicada da obra de arte e a obra múltipla por natureza, possibilitando de maneira crescente uma proximidade impensável através de museus, galerias e exposições. 
Entre os protagonistas dessa democratização se encontram também empresários visando principalmente o lucro, como acontece desde o início da imprensa, em 1455. A arte nunca tinha estado tão próxima ao público indiferenciado. A alienação passaria a dispor de meios cada vez mais poderosos. O desenvolvimento técnico é o mesmo.

O cobre é um metal com muitas virtudes: maleável, dúctil, bom condutor de calor e energia elétrica; sempre foi a melhor escolha para as matrizes de gravura em metal e continua tendo múltiplas aplicações na indústria contemporânea. Pode estar, invisível, em canos embutidos em paredes ou em circuitos dentro de computadores e celulares. Suas virtudes o tornam relativamente caro e visado em roubos, geralmente de cabos elétricos. É o metal mais procurado pelos gravadores na Casa da Boia, que aprendem a evitar os preços do mesmo material transformado em "artístico". Em geral, as matrizes continuam invisíveis como canos e circuitos, já que se costuma expor as estampas impressas, usualmente em papel.

Mas o cobre é visível nas calçadas de São Paulo, junto com outros metais, no trabalho de artesãos, expondo seus trabalhos ao público indiferenciado, preferencialmente em locais de grande movimento. Como os gravadores, procuram a Casa da Boia em busca do metal industrializado para transformá-lo, com o conhecimento disponível, em arte e artesanato.

O artesanato na era industrial usa metais como cobre laminado e ferramentas produzidas em série. A Casa da Boia, propondo tornar-se um espaço expositivo e de discussão sem deixar de ser uma loja de metais industrializados, sugere algumas questões que rondam a Arte Contemporânea. Num lugar que não é propriamente uma galeria, continuando a ser comércio de metais não ferrosos localizado numa rua do centro histórico de São Paulo, onde se concentram as lojas de ferramentas usadas por artistas, artesãos, operários e cidadãos quaisquer em necessidades domésticas, as obras expostas estarão mais no mundo do que em espaços de apresentação artística específicos?

É cedo para tentar uma resposta, se houver. No entanto, é de se esperar que as amplas portas do edifício tombado continuarão abertas para a Rua Florêncio de Abreu, mantendo o espaço mais penetrável que as galerias dedicadas apenas à arte, cuja arquitetura vai tendendo a afastar psicologicamente o público não especializado.

Talvez a obra de Hélio Oiticica mais vista pelo público não iniciado em Arte Contemporânea, ao menos antes da institucionalização do artista, tenha sido a bela capa de "Legal", disco de Gal Costa lançado em 1970. A capa de alguns Ip's era, na época, uma das coisas do mundo que mais possibilitava uma experiência artística visual a um público mais amplo, prioritariamente interessado em música e drogas. Ao bater cocaína e esticar carreiras sobre a capa de War Heroes, de Jimi Hendrix, Hélio Oiticica usava um objeto do mundo ligado à história da estampa e da arte. Aquele disco de vinil fazia parte da história da multiplicação, continuando a propor a experiência paralela, mas continuada - única possível - da música de um grande artista que jamais viria ao Brasil. 
No belo Sobre a Arte Moderna, de 1924, Paul Klee, refletindo sobre as artes visuais e o artista moderno, termina constatando sua ainda escassa relação com a sociedade, o público. Mas haveria uma vasta área das artes visuais a ser também considerada, e outros tipos de artista moderno.

O terreno que as vanguardas pretendiam conquistar já estava ocupado pela indústria gráfica moderna, que há quase um século satisfazia os interesses e afetos visuais da grande maioria da sociedade de massa. Essa expressão desumanizante oculta as enormes diferenças de educação, posses, ocupação, psicologia de uma sociedade agitada, em expansão e urbanização. Queiramos ou não, a produção industrial já vinha moldando as atitudes visuais da sociedade de massas. Não existe público absoluto, mas muitos, que podem se ignorar - e até desprezar.

É inevitável pensar nas mudanças geradas pela industrialização na sensibilidade humana. A mais óbvia visualmente, junto com as paisagens tornadas acessíveis pela velocidade do trem, é a gráfica plenamente industrializada.

Mas os círculos mais cultos e avançados não conseguiam (ou não querem) perceber e aceitar que na produção multiplicada em grande escala, atendendo e dirigindo o gosto muitas vezes vulgar dos muitos públicos, pudesse haver também manifestações artísticas legítimas.

Na Paris do século XIX, eram as ilustrações circulantes em publicações de todos os níveis e quantidades a informar, construir, moldar e deformar o pensamento e a ingenuidade visual do cidadão, que flanava ou seguia os roteiros ditados pelas obrigações nos novos boulevards e galerias, nas travessas, vielas e becos ameaçados, observando as vitrines, os cartazes litográficos, as propagandas, participando do movimento, talvez colecionando as imagens comerciais que mais o atraiam. A pintura impressionista, mesmo exposta em galerias menos refratárias que as de hoje, tinha grande chance se ser ignorada.

O século XIX é o século da gráfica. A fotografia não teria o mesmo impacto se não se desenvolvessem técnicas para associá-la às matrizes de madeira e metal já existentes há séculos e à recente pedra litográfica para multiplicar estampas em papel. A imagem fotográfica revelada e ampliada quimicamente tomou esse caminho para se associar à indústria, aperfeiçoando, por fim, o cliché.

Adoraria ter uma aquarela de Klee.

\section{XIX}

A covid-19 expôs uma série de fatos surpreendentes.

Idosos, pessoas com doenças pré-existentes e pobres são mais frágeis e expostos a doenças. Existem favelas com pessoas amontoadas. Nem todos têm serviços sanitários. O estado e os serviços públicos são necessários. Os pobres precisam de apoio do governo. As condições de trabalho de entregadores e motoboys são degradantes. Alguns correm mais riscos que outros, devido à posição social. Existe uma grande quantidade de presos com AIDS e tuberculose. A ciência tem um papel fundamental na sociedade. A exclusão permite pessoas que sequer são alcançadas pelas notícias e nem sabem o que acontece. O menor tráfico de veículos melhora a qualidade do ar. $O$ artista, ao contrário da noção comum, tende a ser um desconhecido necessitando de apoio. A solidariedade é um valor fundamental.

A vida vale mais que a economia. 
A covid-19 levou ao fechamento, suspensão ou adiamento de espetáculos presenciais: olimpíadas, campeonatos, museus, concertos, galerias, circos, cinemas, teatros, shows, festivais.

Com os espetáculos indisponíveis, aconselham-se inúmeras atrações culturais para manter a saúde mental das pessoas confinadas, como se fosse possível se preparar rapidamente para o imprevisível viver ou construir em pouco tempo uma formação, um salutar pensamento crítico, refletir sobre nossas ações, pensamento e lugar no mundo. Como se não fosse urgente nos dias normais. Como se evento presencial, cultura e arte online fossem coisas separadas.

\begin{abstract}
"Apresentamos o XX/Festival de Vídeos Online, um conjunto de vídeos atuais e históricos que traça um panorama na história da videoarte no Brasil e no mundo. Além de ser uma mídia flexível, que nos permite acesso de onde e quando quisermos, o vídeo talvez seja a mídia que mais assimilou as transformações da contemporaneidade, assumindo seu lugar definitivo nas artes visuais. O festival quer tornar acessível ao público um conteúdo importante para a história da arte e que faz parte do acervo da XX Galeria, com trabalhos de artistas representados além de outros convidados".
\end{abstract}

\# Museu ou Bienal X em casa!

Em tempos normais, a lógica da obra única é imposta ao múltiplo por natureza. O vídeo artístico, longo ou curto, tornado indisponível na internet, pode ser assistido em locais determinados, em pé ou sentado em pouco mais que um caixote, enquanto as melhores salas de cinema se orgulham de seus confortáveis assentos. Como se inutiliza a matriz da gravura artística de edição limitada para elevar o preço e garantir aos possuidores sua exclusividade. A covid-19 - enquanto for uma ameaça mortal -, influi na decisão de permitir o acesso ao que já poderia ser acessível.

$\mathrm{Na}$ alimentação, o delivery atende um público menos vulnerável. Em arte, esporte, turismo e cultura, a multiplicação a distância é a opção de todos que não podem se permitir estar presentes ao evento raro, único, distante, magnifico. As telas vulgares e banais são o grande espaço expositivo contemporâneo onde imagens e sons de todas as naturezas competem. Como o desenho, a pintura, a gráfica, exposição não se limita à arte. Muito antes da imprensa, a efígie de reis e imperadores circulava em moedas, além de sua presença monumental na praça.

Na Atenas clássica, eram aproximadamente 30.000 os cidadãos plenos e democráticos. O teatro de Dionísio comportava cerca de 17.000 espectadores. O espetáculo, após seu encerramento naquele local, continuava reverberando, com duração indefinida, em cada espectador.

Qual é a relação, hoje, entre os assentos teatrais e seu preço, disponíveis em São Paulo, capital, e a totalidade dos habitantes da metrópole que vivem os conflitos da democracia real? Quantos podem pagar um ingresso de cinema? Quantos não se sentem intimidados pela arquitetura de locais de acesso gratuito? 
A noção de espaço público é continuamente mutável, afetada pelo desenvolvimento científico/tecnológico, pelo urbanismo, pelas possibilidades de circulação e comunicação. Quando a polis cresce até a escala da metrópole - que seus próprios habitantes deixam de compreender -, comporta espaços que jamais percorreremos, e uma miríade de imagens e textos circulantes. A estátua do cidadão ilustre na praça só será vista por quem ali passar.

Mas os espaços públicos da cidade - ruas, praças, arquitetura, rios, céu, nuvens -, continuam mentalmente. Em algum momento, o íntimo torna-se político, e vice-versa.

\section{$\mathbf{X X}$}

A Capela Sistina, local sagrado, não foi originalmente concebida para a afluência do público artístico/turístico, com ingresso pago que a mantém permanentemente no limite de capacidade, comprometendo o contato com a famosíssima obra, talvez irritando os mais apaixonados e conscientes. Paciência. A experiência de observar in loco aquelas figuras projetando-se para fora das paredes, impondo ao ser humano a reflexão sobre si mesmo, deve ser acessível a todos. Pelo menos os todos que podem se dirigir a Roma, tem algum interesse pela arte, e reservam uma parte da permanência na cidade aos Museus Vaticanos e sua fila de ingresso.

Michelangelo, ao pintar, levou em conta a distância dos espectadores, cujos olhos, do solo, transformariam em passagens as manchas pinceladas do afresco, claramente visíveis para o artista pintando à distância de seu braço ou nas reproduções disponíveis na internet, em grandeza natural ou ampliadas. Mas não se poderia prever e controlar um público futuro e inesgotável, num espaço de culto de acesso restrito, reservado naquele momento ao Papa, altos dignitários da Igreja Católica, nobres e alguns artistas que lá trabalharam, ou conseguiam acesso mais para apreciar a obra de arte do que para praticar a oração.

Lugar de acesso restrito e controlado, a Capela Sistina, justamente célebre já no século $\mathrm{XVI}$, era mais vista naquela época através das estampas em preto e branco, multiplicadas a partir das matrizes de metal, gravadas por artistas como Giorgio Ghisi, hoje conhecidos apenas por um público estudioso, nos discretos gabinetes de estampas, que sabe reconhecer não apenas o relevante papel de tornar acessível a um público maior a grande obra reservada a poucos, mas a qualidade artística da estampa em si, como trabalho independente, e a atitude crítica indissociável da transformação do grande ambiente pintado a cores, aplicadas sobre superfícies, em linhas gravadas em encavo, onde se depositaria a tinta negra transferida para o papel em dimensões radicalmente reduzidas.

A versão contemporânea e mecanizada da imagem famosa da grande obra é facilmente adquirida na saída, impressa em papel, ou encontrada em forma digital na internet, junto com as imagens gravadas no século XVI. No interior da Capela Sistina, lugar de culto, afinal, procura-se impedir, com sucesso discutível, o ato narcísico desejado por muitos visitantes: uma fotografia inevitavelmente muito ruim, dadas as condições, mas "tirada por mim". Os tantos apaixonados obrigatórios, preparados por tantas imagens e discursos circulantes antecedendo a visita à Capela, chegam a arriscar uma selfie tendo o grande Michelangelo como fundo de si mesmos, a fim de, talvez, postar a imagem nas redes sociais.

"No photos!" é repetido à exaustão pelos vigias vaticanos. A imagem multiplicada continua sendo de controle problemático. 